\title{
Standardized fracture creation in the distal humerus and the olecranon for surgical training and biomechanical testing
}

\author{
Werner Schmoelz ${ }^{1}\left[\mathbb{D} \cdot\right.$ Jan Philipp Zierleyn ${ }^{1} \cdot$ Romed Hoermann $^{2} \cdot$ Rohit Arora $^{1}$
}

Received: 29 April 2021 / Accepted: 27 November 2021 / Published online: 1 January 2022

(c) The Author(s) 2021

\begin{abstract}
Introduction Surgical training and biomechanical testing require models that realistically represent the in vivo injury condition. The aim of this work was to develop and test a method for the generation of distal humerus fractures and olecranon fractures in human specimens, while preserving the soft tissue envelope.

Methods Twenty-one cadaveric upper extremity specimens ( 7 female, 14 male) were used. Two different experimental setups were developed, one to generate distal humerus fractures and one to generate olecranon fractures. Specimens were placed in a material testing machine and fractured with a predefined displacement. The force required for fracturing and the corresponding displacement were recorded and the induced energy was derived of the force-displacement graphs. After fracturing, CT imaging was performed and fractures were classified according to the AO classification.

Results Eleven distal humerus fractures and 10 olecranon fractures with intact soft tissue envelope could be created. Distal humerus fractures were classified as AO type $\mathrm{C}(n=9)$ and as type $\mathrm{B}(n=2)$, all olecranon fractures were classified as AO type $\mathrm{B}(n=10)$. Distal humerus fractures required significantly more load than olecranon fractures $(6077 \mathrm{~N} \pm 1583$ vs $4136 \mathrm{~N} \pm 2368, p=0.038)$ and absorbed more energy until fracture than olecranon fractures $(17.8 \mathrm{~J} \pm 9.1 \mathrm{vs} 11.7 \mathrm{~J} \pm 7.6$, $p=0.11)$, while the displacement at fracture was similar $(5.8 \mathrm{~mm} \pm 1.6$ vs $5.9 \mathrm{~mm} \pm 3.1, p=0.89)$.

Conclusion The experimental setups are suitable for generating olecranon fractures and distal humerus fractures with intact soft tissue mantle for surgical training and biomechanical testing.
\end{abstract}

Keywords Surgical training $\cdot$ Fracture simulation $\cdot$ Olecranon fracture $\cdot$ Distal humerus fracture

\section{Introduction}

In recent years, the training in orthopedic trauma surgery in the theatre was more complemented by hands on cadaver courses and virtual surgical simulation. Due to further specialization and complexity in surgical procedures and implants the professional education and teaching is evolving too. Thereby the traditional concept in surgical training

Werner Schmoelz and Jan Philipp Zierleyn have contributed equally.

Werner Schmoelz

werner.schmoelz@i-med.ac.at

1 Department of Orthopaedics and Traumatology, Medical University of Innsbruck, Anichstraße 35, 6020 Innsbruck, Austria

2 Division Clinical and Functional Anatomy, Medical University of Innsbruck, Innsbruck, Austria of "see one, do one, teach one" [1] should be amended by hands on and simulation training to meet the demands of the public, modern medical systems and the economic pressure [1-3]. After residents first acquire basic surgical skills by taking an assisting role in a surgery, first hands on training and simulations can improve surgical and technical skills prior to performing an operation under supervision. In particular, because orthopedic trauma surgery require not only a competence in managing skeletal trauma but is often also heavily depending on technical skills [3]. There are several different ways to simulate a surgical procedure as realistically as possible such as computer-assisted, virtual reality models, bone surrogate models and cadaver workshops in which a surgery can be practiced on anatomical specimens $[1,4]$. Different studies showed that skills acquired in simulated or hands on training can be transferred from the simulation to the surgery itself $[5,6]$. With a focus on open reduction and internal fixation, Wegmann et al. [7] described a technique for fracture creation in the distal 
radius, by means of a drop test bench. Fresh frozen human forearms are positioned in a drop test bench to simulate a fall onto the outstretched arm. They reported real life clinical fracture patterns with an intact soft tissue mantle. This allows training of fracture treatment including practicing the surgical access with real life haptic and anatomical specimens. Wegmann et al. [7, 8] hypothesized that teaching with pre-fractured fresh frozen anatomical specimens is superior and enables a much closer training of real life situations in cadaver surgery workshops. A feedback survey of a cadaver workshop to improve the operation skills for distal radius fractures received an excellent feedback from the participants [8]. With a drop test bench, they also managed to fracture anatomical specimens for different body sides including the distal humerus and the proximal forearm [7-11]. An alternative setup to fracture creation with a drop test bench could be a setup in a material testing machine. A test setup for pre-fracturing anatomical specimens in a material testing machine will open up new possibilities, because in contrast to drop test benches, material testing machines are available in many institutions and laboratories. Standardized and reproducible fracture creation in anatomical specimen with intact soft tissue envelope could not only be used for surgical training but also for biomechanical investigations of different osteosyntheses techniques and implants. Up to now, the vast majority of comparative biomechanical studies of different osteosyntheses techniques and implants create fracture models by osteotomies $[12,13]$. While they are well standardized and reproducible, they often only approximate real life fracture patters.

Therefore, the aim of the present study was to develop a test setup for creation of standardized and reproducible fractures of the olecranon and distal humerus with an intact soft tissue mantle for surgical teaching of residents and for training of surgeons to further improve their skills in more complex and challenging fractures [14]. Additionally, these fractures shall be evaluated for their potential use in biomechanical testing.

\section{Materials and methods}

Twenty-one alcohol-glycerine-fixed cadaveric upper extremities provided by the Anatomy department of the Medical University of Innsbruck were used. The specimens were harvested from body donors, who had given their written consent for their bodies to be used for scientific and educational purposes. Inclusion criteria for the specimens were no bone injuries or surgical treatment regarding the cubital joint, no rheumatic diseases and an intact soft tissue mantle. The inclusion criteria were controlled for by fluoroscopy and visual inspection. The mean age of the donors was 74 (range 50-96). Seven upper extremities were from female body donors and fourteen from male body donors. Nine of the upper extremities were left/right paired and three were singular.

\section{Specimen preparation and experimental setup}

In a first step, the humeri were prepared to a standardized length of $20 \mathrm{~cm}$ from the distal end and the proximal $5 \mathrm{~cm}$ of the prepared humeri were freed from soft tissue. In the second step, the proximal humeri (approx. $3.5 \mathrm{~cm}$ ) were embedded in epoxy resin (RenCast FC 53 NB + filler DT082 Huntsman, The Woodlands, TX, USA) by use of a purposebuild cylindrical mold. During the embedding process, the longitudinal axis of the humeri was aligned to the axis of the cylindrical embedding Two different experimental setups to create either a humerus fracture or an olecranon fracture were realized in a biaxial servo-hydraulic material testing machine (MTS Mini-Bionix II 858; MTS, Eden Prairie, MN, USA) (Fig. 1). In both setups, the proximal part of the humerus, embedded in epoxy resin, was placed in a guide that allowed movement along the vertical axis and rotation around it, while the forearm was rigidly fixed to the load frame. The displacement induced by the testing machine to

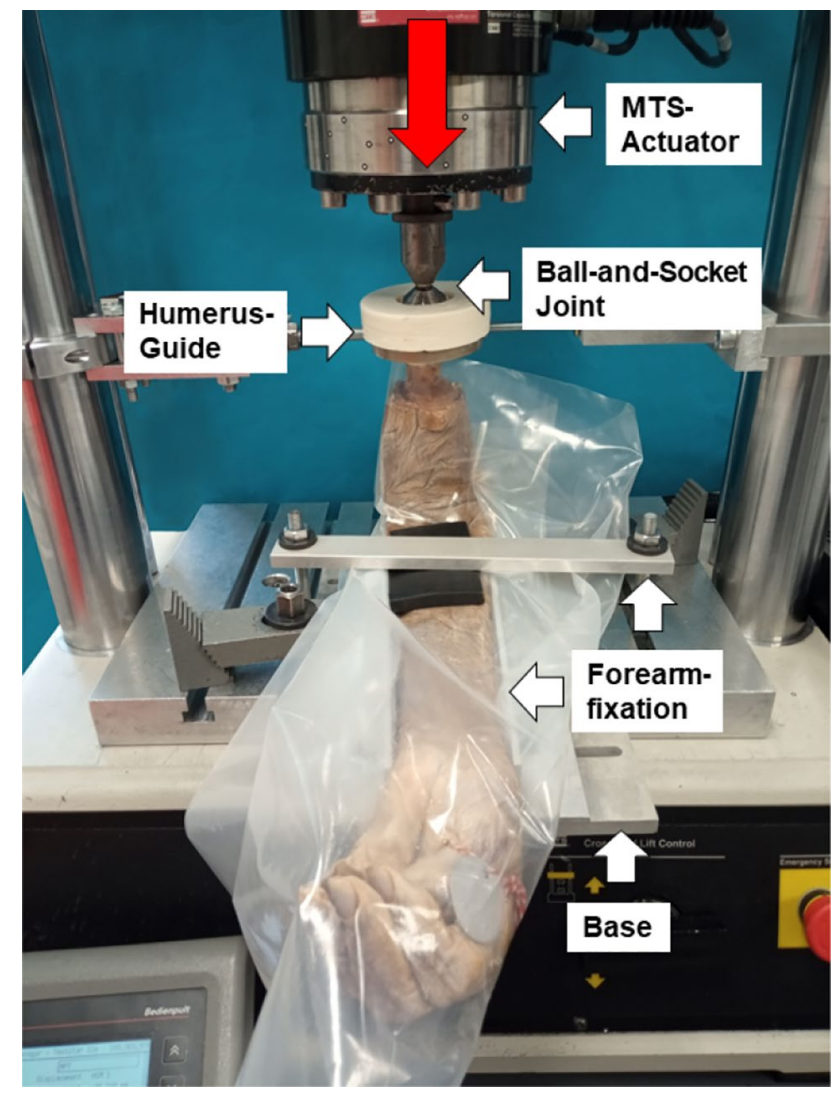

Fig. 1 Setup of specimen loading in a servo-hydraulic material testing machine. The red arrow indicates the load application 
fracture either distal humerus or olecranon was transmitted from the actuator of the testing machine to the specimen via a ball and socket joint between the actuator and the proximal part of the embedded humerus.

To create a humerus fracture the cubital joint was positioned to approximately $105^{\circ}$ flexion and a mechanical stop was placed at the olecranon to prevent slippage and fracture of the olecranon (Fig. 2a). To provoke a fracture of the olecranon, the angle in the cubital joint was set to $90^{\circ}$ flexion and the olecranon was positioned in the load frame of the material testing machine with an offset of approx. $15 \mathrm{~mm}$ over the base plate to create a predetermined breaking point (Fig. 2b).

For fracture creation, the specimens were subjected to a preload of $50 \mathrm{~N}$ followed by an impact of $10 \mathrm{~mm}$ (displacement controlled ramp with $100 \mathrm{~mm} / \mathrm{s}$ ). After loading, the fracture was verified by fluoroscopy. If no fracture was detected in the fluoroscopy, image loading was repeated with a higher impact displacement $(15 \mathrm{~mm})$. During the experiment, the displacement of the actuator, associated force and time were recorded with a sample rate of $1000 \mathrm{~Hz}$.

Subsequent to fracture verification by fluoroscopy, a clinical CT (LightSpeed VCT 16, GE Healthcare, Chicago, USA) was conducted and one observer classified the fractures according to the current AO-classification system and Mayo classification $[15,16]$. To measure the trabecular bone mineral density (BMD) of the distal radius based on a combination of the techniques described by Burt et al. [17] and Krappinger et al. [18] was used. In the region of interest described by Burt et al. [17], three measurements were performed similar to Krappinger et al. [18].

The maximum force occurring during fracture and the corresponding displacement were derived of the force-displacement graphs. The energy absorbed by the test objects until fracture was calculated by numerical integration of the force-displacement curve. After maximum force, the plots showed a steep drop, therefore, the energy absorption was calculated up to the displacement occurring at the maximum applied force.

\section{Statistical analysis}

A $t$ test was used for comparison of the maximum force, energy and displacement of olecranon and humerus fractures. In the SPSS software package (IBM SPSS Statistics, Version 24.0.0.1, IBM Corporation, Armonk, New York, USA), a Pearson correlation was used to examine the correlation of the measured BMD and the maximum applied force, energy and displacement.

\section{Results}

With the setup designed for distal humerus fractures in 11 of the 15 loaded specimens the desired fracture could be created (73\%), in 4 specimens loading in the distal humerus setup resulted in an olecranon fracture. With the setup intended for olecranon fractures, the desired fracture type could be created in all specimens $(100 \%)$.

Fractures of the distal humerus showed a significant higher maximum force than fractures of the olecranon ( $6077 \mathrm{~N} \pm 1583$ vs $4136 \mathrm{~N} \pm 2368$; $p=0.038$ ). The corresponding displacement at maximum force for the humerus fractures was $5.8 \mathrm{~mm} \pm 1.6 \mathrm{~mm}$ and $5.9 \mathrm{~mm} \pm 3.1 \mathrm{~mm}$ for the olecranon fracture $(p=0.89)$. The energy absorption
Fig. 2 Close up view of the setup for specimen fixation in a load frame for generation of humerus fractures (a) and of olecranon fractures $(\mathbf{b})$
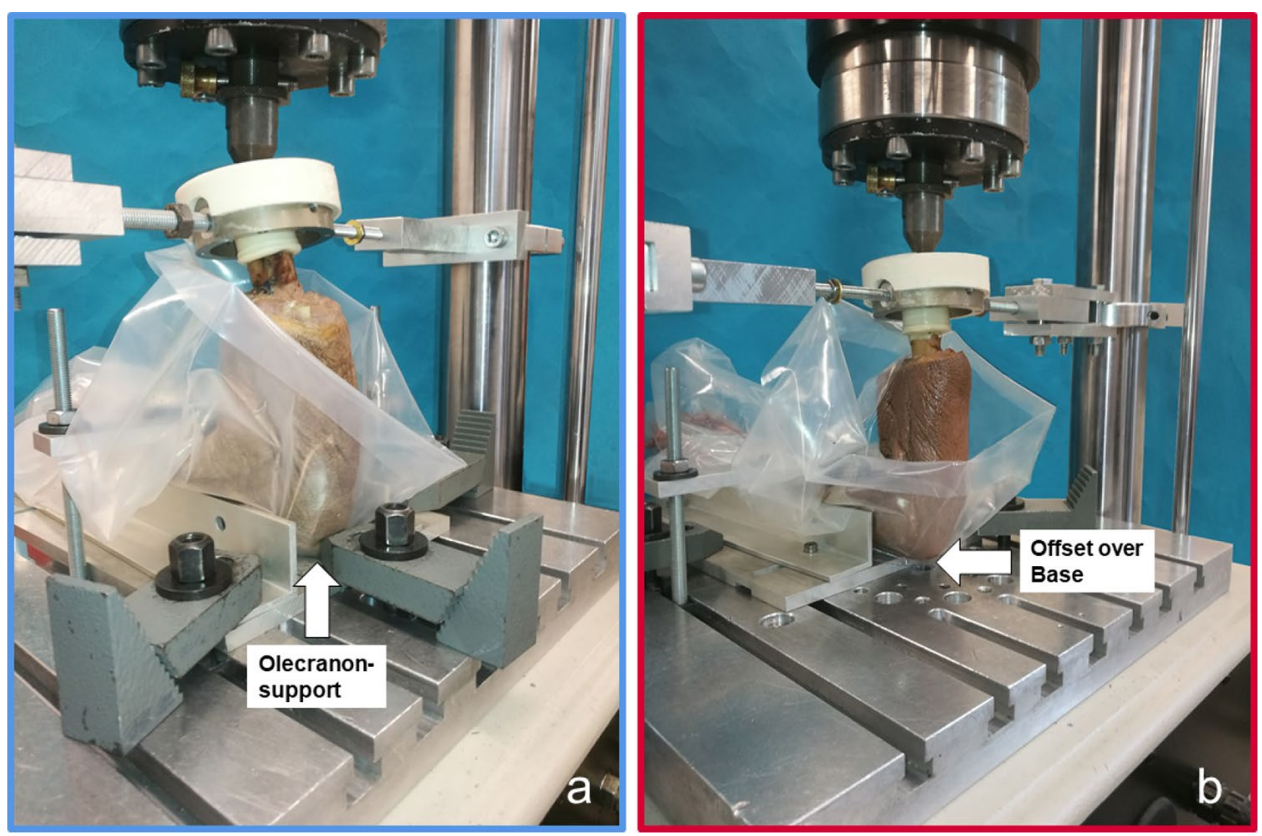
until maximum fracture load was $17.8 \mathrm{~J} \pm 9.1$ for distal humerus fractures versus $11.7 \mathrm{~J} \pm 7.6$ fore olecranon fractures $(p=0.11)$ (Tables 1, 2; Fig. 3).

The average trabecular BMD of the distal radius of the specimens was $118 \mathrm{mg} / \mathrm{cm}^{3} \pm 48$. Correlating the BMD with parameters of the fracture creation showed a significant correlation with the maximum load $(R=0.92, p<0.0001)$ and absorbed energy $(R=0.677, p=0.022)$ for distal humerus fractures and with the maximal load $(R=0.701, p=0.024)$ and absorbed energy $(R=0.691, p=0.027)$ for olecranon fractures (Fig. 4). No correlation with displacement was found for either humerus fractures $(R=0.337, p=0.31)$ or olecranon fractures $(R=0.387, p=0.269)$.

Regarding the fracture classification according to the AO, 8 of the 11 distal humerus fractures showed an AO type C fracture with a similar fracture pattern (Fig. 5). Thereby, the medial part of the condyle was separated by a fracture parallel to the longitudinal axis through middle of epiphysis and metaphysis, extending up to the transition to the diaphysis. Additionally, a second transvers fracture line, running just above or below the transcondylar axis separated the capitulum humeri from the metaphysis in most cases. In some of these cases, the transverse fracture line also separated the trochlea humeri from the before described medial fragment. Two of the distal humerus fractures were classified as AO type B fractures, one with the capitulum humeri and one with the trochlear humeri staying intact. One more showed a complete articular fracture with a fracture pattern that presents in shape of a capital $\mathrm{T}$ in coronal plane with the cross at the transition from metaphysis to diaphysis.

All olecranon fractures were classified as AO type B fractures. In all fractures, the olecranon was separated from the ulna by a fracture line running through the bare area or slightly proximal. Additionally, the olecrani were
Table 1 Overview of specimens with humerus fractures

\begin{tabular}{|c|c|c|c|c|c|}
\hline \multicolumn{6}{|c|}{ Humerus fractures } \\
\hline Specimen & $\begin{array}{l}\text { AO fracture } \\
\text { classification }\end{array}$ & Max. force $(\mathrm{N})$ & $\begin{array}{l}\text { Displacement at } \\
\text { max force }(\mathrm{mm})\end{array}$ & Energy $(\mathrm{J})$ & Tb. BMD $\left(\mathrm{mg} / \mathrm{cm}^{3)}\right.$ \\
\hline AG101L & $13 \mathrm{~B} 1.3$ & 6477 & 6.0 & 20.6 & 97 \\
\hline AG105L & $13 \mathrm{~B} 2.3$ & 5692 & 5.9 & 14.7 & 118 \\
\hline AG107R & $13 \mathrm{C} 1.1$ & 6177 & 4.7 & 14.1 & 141 \\
\hline AG106R & $13 \mathrm{C} 2.2$ & 6249 & 4.5 & 14.7 & 103 \\
\hline AG101R & $13 \mathrm{C} 3.1$ & 6614 & 6.5 & 19.6 & 117 \\
\hline AG107L & $13 \mathrm{C} 3.1$ & 6025 & 3.9 & 13.3 & 138 \\
\hline AG109R & $13 \mathrm{C} 3.1$ & 3438 & 6.5 & 9.9 & 27 \\
\hline AG102L & $13 \mathrm{C} 3.2$ & 7243 & 7.4 & 19.1 & 147 \\
\hline AG104R & $13 \mathrm{C} 3.2$ & 8732 & 9.5 & 42.5 & 177 \\
\hline AG106L & $13 \mathrm{C} 3.2$ & 6993 & 5.9 & 18.2 & 121 \\
\hline AG109L & $13 \mathrm{C} 3.2$ & 3211 & 4.6 & 8.4 & 34 \\
\hline Mean \pm SD & & $6077 \pm 1583$ & $5.8 \pm 1.6$ & $17.8 \pm 9.1$ & $111 \pm 46$ \\
\hline
\end{tabular}

Table 2 Overview of specimens with olecranon fractures

\begin{tabular}{|c|c|c|c|c|c|c|}
\hline \\
\hline \multicolumn{7}{|c|}{$\begin{array}{ll}\text { Olecranon fractures } \\
\text { Specimen } & \begin{array}{l}\text { AO fracture clas- } \\
\text { sification }\end{array}\end{array}$} \\
\hline AG103R & 2U1B1 & II B & 2504 & 5.0 & 7.9 & 145 \\
\hline AG104L & 2U1B1 & II B & 7927 & 5.8 & 24.9 & 49 \\
\hline AG105R & 2U1B1 & II B & 6131 & 8.1 & 18.6 & 78 \\
\hline AG108R & 2U1B1 & II B & 2583 & 3.5 & 5.1 & 146 \\
\hline AG111R & 2U1B1 & I A & 6231 & 6.8 & 16.6 & 207 \\
\hline AG102R & 2U1B1 & II B & 6720 & 3.9 & 13.3 & 165 \\
\hline AG103L & 2U1B1 & II B & 1348 & 3.4 & 2.7 & 69 \\
\hline AG108L & 2U1B1 & I B & 1868 & 3.6 & 3.3 & 178 \\
\hline AG110L & 2U1B1 & II B & 3566 & 13.6 & 18.1 & 112 \\
\hline AG112R & 2U1B1 & II B & 2478 & 5.8 & 6.9 & 102 \\
\hline Mean \pm SD & & & $4136 \pm 2368$ & $5.9 \pm 3.1$ & $11.7 \pm 7.6$ & $125 \pm 52$ \\
\hline
\end{tabular}


Fig. 3 Boxplot of maximum force at fracture and absorbed energy until fracture
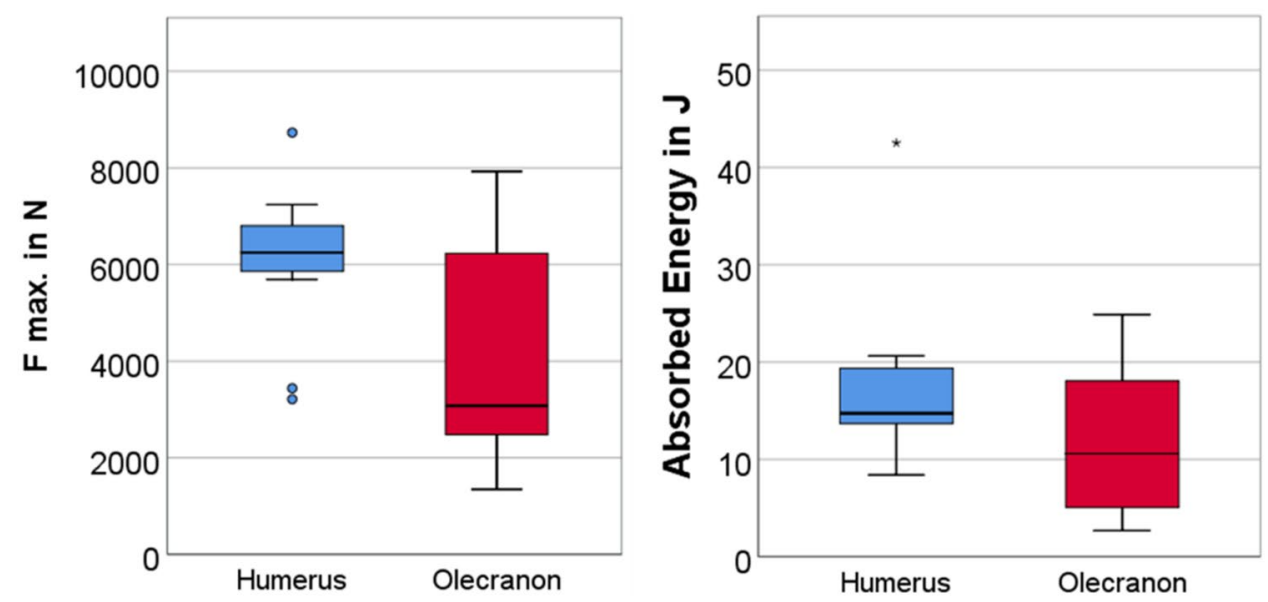

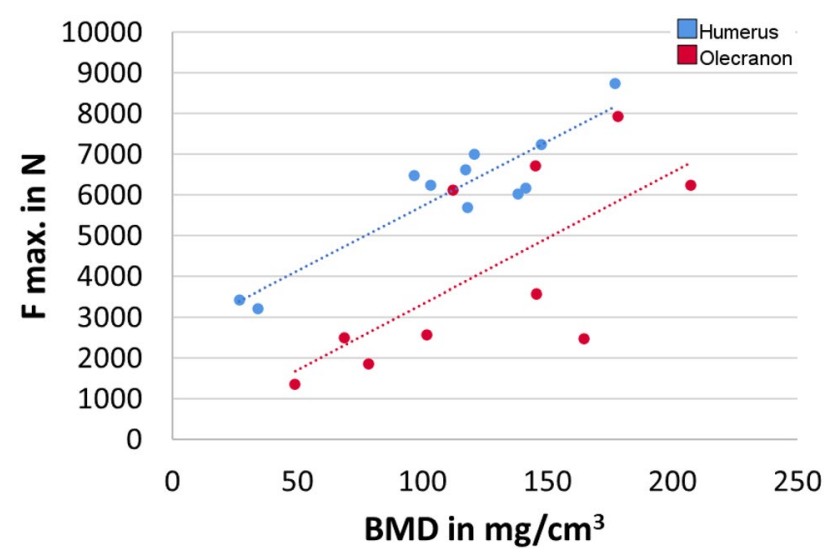

Fig. 4 Correlation of BMD with maximum force at fracture

fragmented in varying manners and showed a heterogenic fracture pattern (Fig. 6). One olecranon fracture was a simple olecranon fracture, while nine were multi-fragmental fractures. Four showed a distinct impression of the articular surface. According to the Mayo classification, eight olecranon fractures were classified as type II B, one as type I A and one as type I B.

\section{Discussion}

The study shows that with the chosen experimental setups, it was possible to selectively produce either fractures of distal humerus or olecranon with an intact soft tissue mantle. The skin showed only some minor signs of injury manifested by pressure marks and small cuts similar as they can occur in real life injuries. These minor skin injuries still allow the training of the surgical access for the fracture treatment.

Of the two fracture types, the setup for olecranon fractures worked particularly well and generated the desired fracture type in all the specimens it was applied to (100\%).
The radiological assessment of olecranon fractures showed variable fracture patterns. This might be due to anatomical variations in size and shape of the used specimens. A more uniform fracture pattern with less complex two part fracture pattern might be achieved by increasing the cubital flexion angle and apply the loading with a stepwise increased displacement until a fracture is present.

With the experimental setup for generation of distal humerus fractures, the desired fracture could be generated in 11 of 15 specimens (73\%). In 4 of the 15 trials, olecranon fractures instead of intended humerus fractures were created (27\%). The unintended olecranon fractures with the setup for the distal humerus tended to be more complex and likely pose a greater challenge for surgical treatment in training courses. The success rate for distal humerus fractures might be improved, by changing the support and mechanical stop of olecranon to prevent the dislocation during fracture generation to a custom fit support and fixation of the olecranon (e.g. a plaster cast, or mold with epoxy resin).

Considering the different success rate in fracture creation and cross-overs of the distal humerus and olecranon fractures, if an equal number of the two fracture locations is desired, it is recommended to start with distal humerus fractures.

The aim of the study was to develop and design experimental setups capable of reproducibly generating the desired fracture type with realistic fracture patterns and mechanism. Comparing the fracture mechanism and fracture pattern of the distal humerus fractures with clinical studies showed a good agreement for distal humerus fractures [19, 20].

The created olecranon fractures show comparable fracture patterns as reported in the literature for complex olecranon fractures [21]. However, in an epidemiological study on ulna fractures, Duckworth et al. [22] observed a higher percentage of less complex and simpler two part fractures of the olecranon than created with the presented setup. A less complex two-part fracture pattern might be achieved 

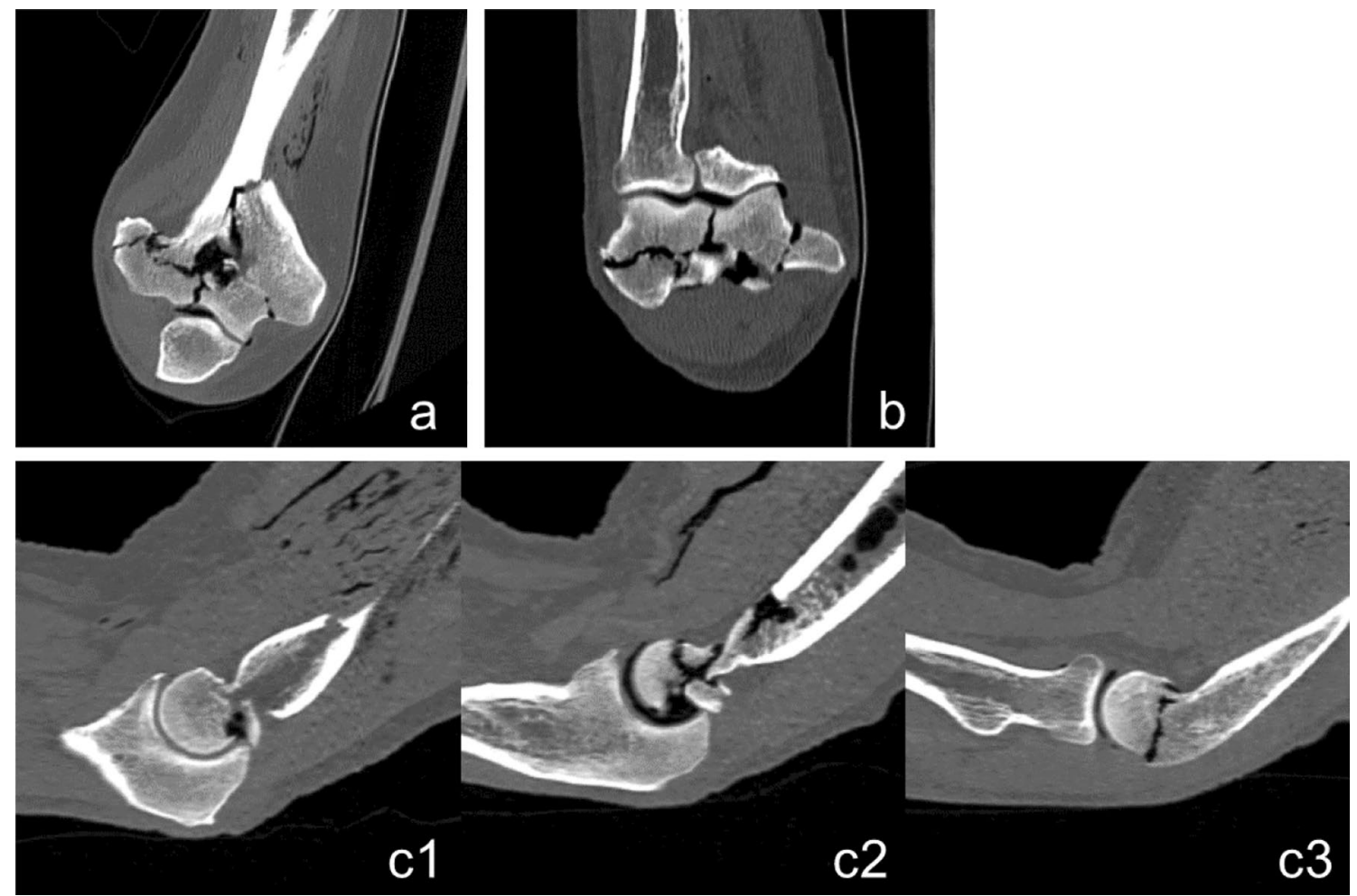

Fig. 5 Exemplary CT cross sections of a typical humerus fracture pattern (AO-classification 13C3.2) a coronal plane, b axial plane, c1-c3 sagittal plane

by increasing the cubital flexion angle and reducing the displacement applied for fracture creation.

The trabecular BMD of the distal radius in the fractured specimens correlated well with the maximum fracture load and the absorbed energy until fracture. This is in accordance to the reports in the literature reporting the bone morphology of the distal radius being a good predictor for fragility fractures [23]. Recently, Marcoin et al. fractured isolated distal humeri for a biomechanical study and also reported a correlation between the fracture load and BMD [24].

Using pre-fractured specimens for surgical training courses has a more than 20-year-long tradition at our institution. Initially, forearm fractures were created with manual hydraulic devices, followed by manual fracture creation in a material testing machine up to the current setup with a simulated impact with a servo-hydraulic material machine. In the literature, fracture creation in anatomical specimens is described either by dropping a dead weight or by the use of a material testing machine [7, 9-11, 25-27]. In drop dead weight, fracture generation specimens are subjected to an impact with a predefined amount of energy with an optional limit of the displacement, while in material testing machines, specimens are subjected to an impact with a predefined displacements or force with an unlimited amount of energy. Therefore, a comparison of the applied energy for fracture creation in drop dead weight tests and material testing machines are not very meaningful. E.g Wegmann et al. [7] reported an average impact of $134.7 \mathrm{~J}$ for fracture creation in distal radius specimens, while in the current study, the energy to fracture either the distal humerus or the olecranon was substantially less. This can be explained by the fact, that for material testing machine setups usually the energy absorbed by the specimen until fracture is calculated with the applied force and displacement, while in drop dead weights setups, the impact energy is calculated with the gravity force of the dead weights and their drop height. However, parts of the input energy in drop dead weight tests might also be absorbed by the mechanical stop limiting the displacement or the soft tissue. To allow an energy comparison of the two test setups, the energy, the applied force and displacement until fracture in drop dead weight tests should be recorded and used to calculate the absorbed energy of the specimen until fracture.

Another possible application for pre-fractured specimens could be in biomechanical testing and comparison of different fracture stabilizations. While the presence of real life fractures is a crucial factor in surgical training, it is also important in the field of biomechanical testing and comparison of different fracture stabilizations. Up to now, the standard for fracture simulation in biomechanical testing is the creation of a fracture by standardized osteotomies $[12,13]$. This allows the comparison of different 
Fig. 6 Exemplary CT cross sections illustrating the heterogenic fracture patterns of four different olecranon fractures (AO-classification a-d U1B1, Mayo classification a type I A, b-d type II B)
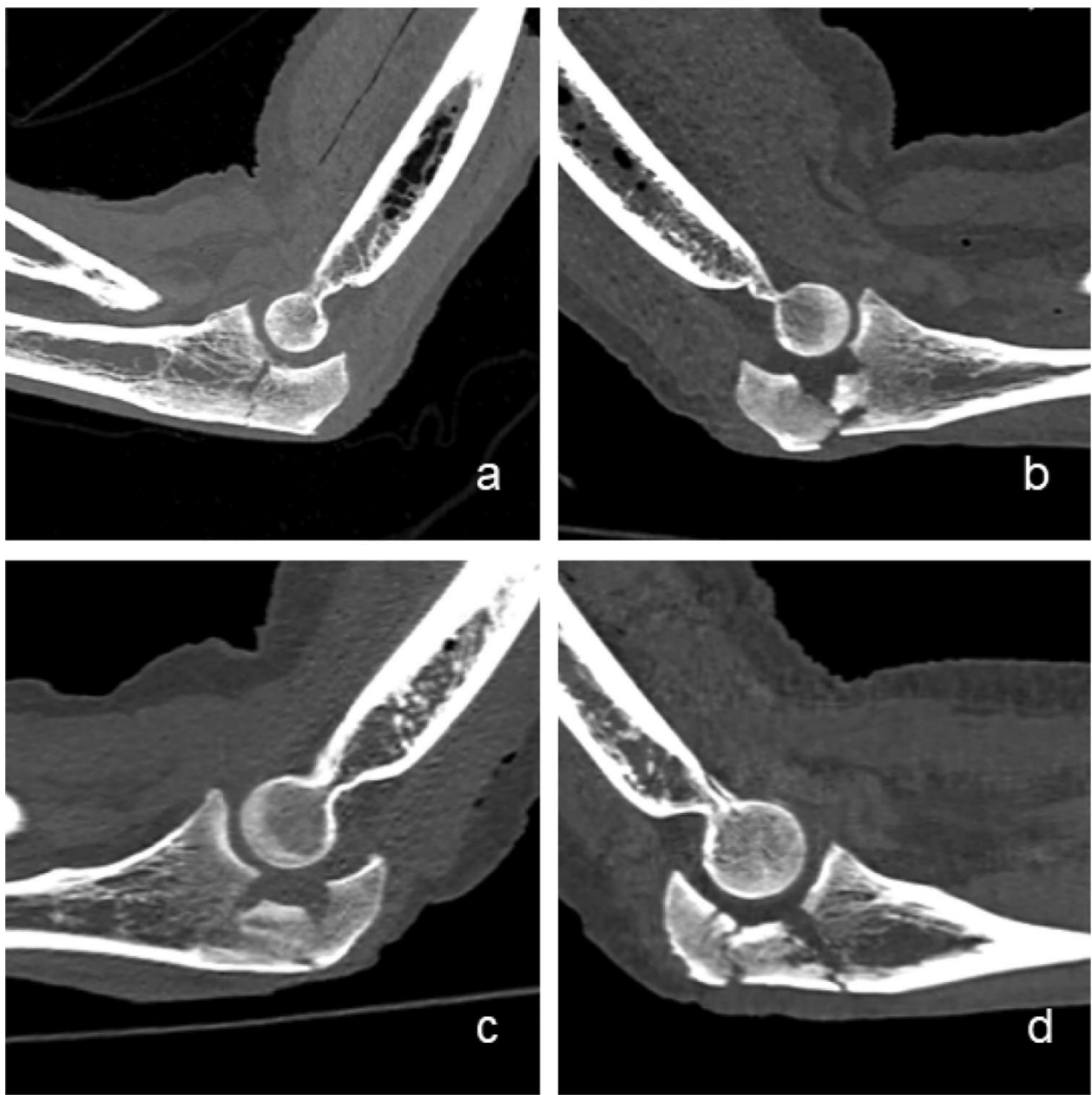

fracture stabilization treatments in comparable instabilities. However, with a standardized and reproducible technique to create real life fracture patterns in specimens, biomechanical studies on fracture stabilizations will also move from idealized fracture patterns closer to the real life applications of the fracture stabilization techniques. The designed and tested setups for fracture generation in the present study resulted in a variation of real life fracture patterns. Therefore, prior to their application for biomechanical comparison of fracture stabilization techniques, the setups will have to be further optimized to narrow down the variation in fracture patterns to limit the number specimens required to obtain comparable test groups for comparison of fracture treatment techniques.

A limitation of the present study is the use of alcoholglycerine fixed cadaveric upper extremities for the experiments. However, it can be assumed that the setups for fracture creation of distal humerus and olecranon fractures will work equally well with fresh frozen specimens, only the maximum force until fracture and its corresponding displacement as well as the required energy until fracture might vary slightly [28].

Concluding the designed and tested setups for fracture creation with an intact soft tissue envelope in distal humerus fractures and olecranon fractures are capable of producing a range of real life fracture types and patterns for surgical training courses, while for biomechanical testing and comparison of fracture stabilization procedures, a more homogenized fracture pattern would be desirable.

Acknowledgements The authors sincerely thank those who donated their bodies to science so that anatomical research could be performed. Results from such research can potentially increase mankind's overall knowledge that can then improve patient care. Therefore, these donors and their families deserve our highest gratitude.

Funding This study was funded by AO-Trauma Austria. The funding source was not involved in study design; in the collection, analysis and interpretation of data; in the writing of the report; and in the decision to submit the article for publication. 


\section{Declarations}

Conflict of interest The authors declare that they have no conflict of interest.

Research involving human participants and/or animals This article does not contain any studies with human participants or animals.

Informed consent The specimens used in this laboratory study were harvested from body donors, who had given their written consent for their bodies to be used for scientific and educational purposes.

Open Access This article is licensed under a Creative Commons Attribution 4.0 International License, which permits use, sharing, adaptation, distribution and reproduction in any medium or format, as long as you give appropriate credit to the original author(s) and the source, provide a link to the Creative Commons licence, and indicate if changes were made. The images or other third party material in this article are included in the article's Creative Commons licence, unless indicated otherwise in a credit line to the material. If material is not included in the article's Creative Commons licence and your intended use is not permitted by statutory regulation or exceeds the permitted use, you will need to obtain permission directly from the copyright holder. To view a copy of this licence, visit http://creativecommons.org/licenses/by/4.0/.

\section{References}

1. Kotsis SV, Chung KC (2013) Application of the "see one, do one, teach one" concept in surgical training. Plast Reconstr Surg 131(5):1194-1201. https://doi.org/10.1097/PRS.0b013e3182 $87 \mathrm{a} 0 \mathrm{~b} 3$

2. Michelson JD (2006) Simulation in orthopaedic education: an overview of theory and practice. J Bone Jt Surg Am 88(6):14051411. https://doi.org/10.2106/JBJS.F.00027

3. Marchand LS, Sciadini MF (2020) Simulation training in fracture surgery. J Am Acad Orthop Surg 28(21):e939-e947. https:// doi.org/10.5435/JAAOS-D-20-00076

4. Morgan M, Aydin A, Salih A, Robati S, Ahmed K (2017) Current status of simulation-based training tools in orthopedic surgery: a systematic review. J Surg Educ 74(4):698-716. https:// doi.org/10.1016/j.jsurg.2017.01.005

5. Egol KA, Phillips D, Vongbandith T, Szyld D, Strauss EJ (2015) Do orthopaedic fracture skills courses improve resident performance? Injury 46(4):547-551. https://doi.org/10.1016/j.injury. 2014.10.061

6. Larsen CR, Soerensen JL, Grantcharov TP, Dalsgaard T, Schouenborg L, Ottosen C et al (2009) Effect of virtual reality training on laparoscopic surgery: randomised controlled trial. BMJ 338:b1802. https://doi.org/10.1136/bmj.b1802

7. Wegmann K, Harbrecht A, Hackl M, Uschok S, Leschinger T, Müller LP (2020) Inducing life-like distal radius fractures in human cadaveric specimens: a tool for enhanced surgical training. Arch Orthop Trauma Surg 140(3):425-432. https://doi.org/ 10.1007/s00402-019-03313-5

8. Wegmann K, Rausch V, Burkhart KJ, Hackl M, Leschinger T, Müller L (2019) Advanced surgical trauma care course - evaluation of a fracture simulation course concept with intact soft tissue. Z Orthop Unfall. https://doi.org/10.1055/a-0983-8322

9. Wegmann K, Ott N, Hackl M, Leschinger T, Uschok S, Harbrecht A et al (2020) Simulation of life-like distal humerus and olecranon fractures in fresh frozen human cadaveric specimens.
Obere Extremität 15(2):137-141. https://doi.org/10.1007/ s11678-020-00573-1

10. Harbrecht A, Rausch V, Wegmann K, Hackl M, Uschok S, Leschinger $T$ et al (2020) Fractures around the hip: inducing life-like fractures as a basis for enhanced surgical training. Arch Orthop Trauma Surg. https://doi.org/10.1007/ s00402-020-03628-8

11. Ott N, Harbrecht A, Hackl M, Leschinger T, Knifka J, Müller LP et al (2021) Inducing pilon fractures in human cadaveric specimens depending on the injury mechanism: a fracture simulation. Arch Orthop Trauma Surg 141(5):837-844. https://doi.org/10. 1007/s00402-020-03538-9

12. Dankl L, Schmoelz W, Hoermann R, Euler S (2020) Evaluation of mushroom-shaped allograft for unstable proximal humerus fractures. Arch Orthop Trauma Surg. https://doi.org/10.1007/ s00402-020-03715-w

13. Buijze GA, Blankevoort L, Tuijthof GJ, Sierevelt IN, Kloen P (2010) Biomechanical evaluation of fixation of comminuted olecranon fractures: one-third tubular versus locking compression plating. Arch Orthop Trauma Surg 130(4):459-464. https:// doi.org/10.1007/s00402-009-0980-z

14. Mighell MA, Stephens B, Stone GP, Cottrell BJ (2015) Distal humerus fractures: open reduction internal fixation. Hand Clin 31(4):591-604. https://doi.org/10.1016/j.hcl.2015.06.007

15. Meinberg EG, Agel J, Roberts CS, Karam MD, Kellam JF (2018) Fracture and dislocation classification compendium-2018. J Orthop Trauma 32(Suppl 1):S1-S170. https:// doi.org/10.1097/BOT.0000000000001063

16. Sullivan CW, Desai K (2019) Classifications in brief: Mayo classification of olecranon fractures. Clin Orthop Relat Res 477(4):908-910. https://doi.org/10.1097/CORR.0000000000 000614

17. Burt LA, Liang Z, Sajobi TT, Hanley DA, Boyd SK (2016) Sex- and site-specific normative data curves for HR-pQCT. J Bone Miner Res 31(11):2041-2047. https://doi.org/10.1002/ jbmr.2873

18. Krappinger D, Roth T, Gschwentner M, Suckert A, Blauth M, Hengg C et al (2012) Preoperative assessment of the cancellous bone mineral density of the proximal humerus using CT data. Skelet Radiol 41(3):299-304. https://doi.org/10.1007/ s00256-011-1174-7

19. Popkin CA, Rosenwasser KA, Ellis HB (2017) Pediatric and adolescent T-type distal humerus fractures. J Am Acad Orthop Surg Glob Res Rev 1(8):e040. https://doi.org/10.5435/JAAOS Global-D-17-00040

20. Iwamoto T, Suzuki T, Matsumura N, Nakamura M, Matsumoto M, Sato K (2017) Lateral para-olecranon approach for the treatment of distal humeral fracture. J Hand Surg Am 42(5):344350. https://doi.org/10.1016/j.jhsa.2017.02.004

21. Okamoto M, Namba J, Kuriyama K, Miyamura S, Yokoi H, Yamamoto K (2020) Surgical technique in tension band wiring method for selected comminuted olecranon fractures. Eur J Orthop Surg Traumatol 30(2):237-242. https://doi.org/10.1007/ s00590-019-02551-y

22. Duckworth AD, Clement ND, Aitken SA, Court-Brown CM, McQueen MM (2012) The epidemiology of fractures of the proximal ulna. Injury 43(3):343-346. https://doi.org/10.1016/j. injury.2011.10.017

23. Burt LA, Manske SL, Hanley DA, Boyd SK (2018) Lower bone density, impaired microarchitecture, and strength predict future fragility fracture in postmenopausal women: 5-year follow-up of the calgary CaMos cohort. J Bone Miner Res 33(4):589-597. https://doi.org/10.1002/jbmr.3347

24. Marcoin A, Eichler D, Kempf JF, Clavert P (2020) Biomechanical model of distal articular humeral fractures-influence of bone 
density on the fracture threshold. Int Orthop 44(7):1385-1389. https://doi.org/10.1007/s00264-020-04624-8

25. Pechlaner S, Kathrein A, Gabl M, Lutz M, Angermann P, Zimmermann $\mathrm{R}$ et al (2002) Distal radius fractures and concomitant lesions. Experimental studies concerning the pathomechanism. Handchir Mikrochir Plast Chir 34(3):150-157. https://doi.org/ $10.1055 / \mathrm{s}-2002-33682$

26. Hamilton DA, Reilly D, Wipf F, Kamineni S (2015) Comminuted olecranon fracture fixation with pre-contoured plate: comparison of composite and cadaver bones. World J Orthop 6(9):705-711. https://doi.org/10.5312/wjo.v6.i9.705

27. Wegmann K, Engel K, Burkhart KJ, Ebinger M, Holz R, Brüggemann GP et al (2014) Sequence of the Essex-Lopresti lesion-a high-speed video documentation and kinematic analysis. Acta Orthop 85(2):177-180. https://doi.org/10.3109/17453 674.2014.887952

28. Unger S, Stefan U, Blauth M, Michael B, Schmoelz W, Werner S (2010) Effects of three different preservation methods on the mechanical properties of human and bovine cortical bone. Bone 47(6):1048-1053. https://doi.org/10.1016/j.bone.2010.08.012

Publisher's Note Springer Nature remains neutral with regard to jurisdictional claims in published maps and institutional affiliations. 